\title{
Epistemologia Positivista: Qual a Sua Influência Hoje?
}

Positivism: What is your influence today?

Alexandre Magno

Dias Silvino

Instituto de

Ciências do Trabalho

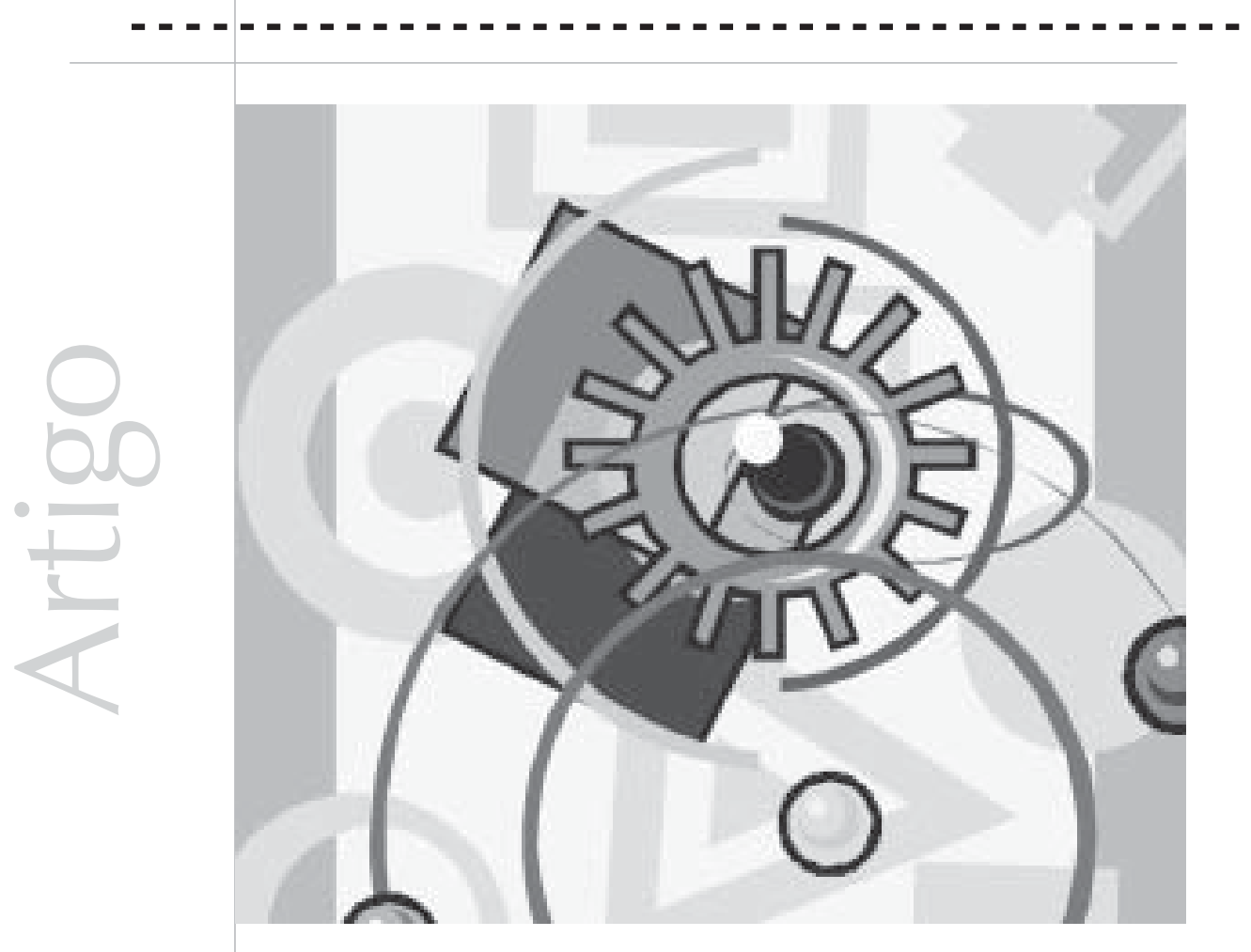




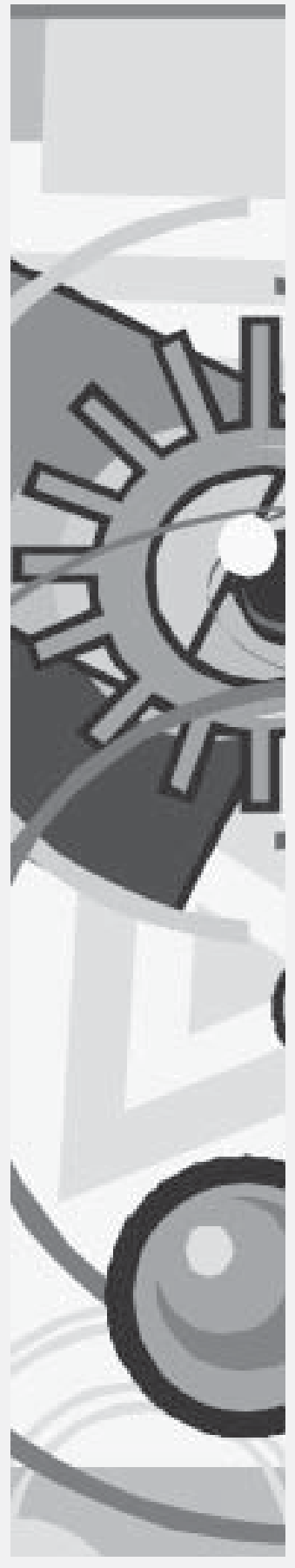

Resumo: O que é ciência? Essa questão continua pertinente. Banalizada por uns ou valorizada ao extremo por outros, a verdade é que ela ganha força sempre que uma área do conhecimento se pretende científica. A flexibilização - ou mesmo substituição - dos critérios de demarcação contemporâneos é seu mote principal, o que confere à discussão um tom maniqueísta entre positivismo versus pós-modernismo. Nessa discussão, diferentes disciplinas são classificadas como positivistas, apesar das suas divergências filosóficas, teóricas e metodológicas. Mas parece plausível chamar a epistemologia hegemônica de positivista? O objetivo deste artigo é mostrar que o rótulo é inadequado, apesar da influência do positivismo. Para tanto, são articulados três argumentos: o positivismo está circunscrito historicamente; o sentido de investigação, fundamentalmente dedutivo, da ciência contemporânea constitui um rompimento com ele, e a classificação de positivismo adotada coloca, sob a mesma égide, disciplinas essencialmente distintas.

Palavras-chave: epistemologia, positivismo, pós-modernismo, ciência

Abstract: The question what is science remains pertinent. Although taken for granted by some, and over-estimated by others, the issue gets stronger every time a new subject tries to reach a scientific status. The bending or even the replacement - of the contemporary criteria used to define what is scientific is the central topic of this discussion that has gained manichaeist aspects, focusing the opposition between positivism and post-modernism. Within this debate, many subjects are considered to be positivists, despite their philosophical, theoretical and methodological differences. Taking this into account, would it be possible to call positivism the hegemonic epistemology? The main goal of this article is therefore to show that, in spite of the influences of positivism, this is an inadequate label. This idea will be supported by three main arguments: (i) positivism is limited to a historical context; (ii) the deductive sense of contemporary investigation represents a rupture with the concept of positivism; and (iii) the rules of classification adopted by positivism groups subjects that are essentially diverse.

Key words: epistemology, positivism, post-modernism, science. 
Em sua obra intitulada O Mundo Assombrado pelos Demônios, Carl Sagan (1998) discute o papel da ciência na história humana. Ele defende a idéia de que o método científico seja uma das formas de produção de conhecimentos mais bem sucedidas por gerar diferentes situações em que o homem pôde superar seus limites e transformar a sua interrelação com a natureza. A extinção de doenças endêmicas, a "conquista" do espaço, a decodificação genética, os adventos do rádio, da televisão, do telefone, do laser, dentre outras tantas maravilhas produzidas, tem seu fundamento na produção de conhecimentos científicos.

Sagan (1998) critica o que ele chama de analfabetismo científico e a ascensão das chamadas pseudociências e do irracionalismo diante de acontecimentos enigmáticos ou não. Segundo esse autor, “... as conseqüências do

As chamadas ciências naturais e biológicas continuam gerando

conhecimentos que sustentam uma evolução tecnológica para facilitar a vida das pessoas lo que não significa ignorar que a tecnologia, em casos específicos, causa mais transtornos do que auxilia). analfabetismo científico são muito mais perigosas em nossa época do que em qualquer outro período anterior" (p.21), devido à grande penetração que a tecnologia tem hoje na formação da sociedade e nas perspectivas dessa relação em futuro próximo.

As chamadas ciências naturais e biológicas continuam gerando conhecimentos que sustentam uma evolução tecnológica para facilitar a vida das pessoas (o que não significa ignorar que a tecnologia, em casos específicos, causa mais transtornos do que auxilia). Da mesma forma, as ciências sociais têm buscado, com mérito, mas em proporção diferenciada, prestar as suas contribuições. $\mathrm{Na}$ busca pela compreensão do fenômeno social, e, num recorte mais fino, do próprio homem, os pesquisadores sociais têm enfrentado dificuldades de naturezas distintas, que vão desde a variabilidade do seu "objeto de estudo" até a própria escolha do método e dos instrumentos produzidos para alcançar seus objetivos. Talvez a maior dificuldade tenha sua gênese na filosofia que embasa suas escolhas e que orienta a relação entre o método e o objeto de estudo.
Um embate recorrente no meio acadêmico tem, como foco, o conceito de ciência e o seu critério de demarcação. Essa discussão assume diferentes magnitudes a depender do foco, por exemplo: pesquisa qualitativa vs pesquisa quantitativa, subjetividade vs objetividade, holismo vs reducionismo. Malgrado as menções pejorativas muitas vezes impregnadas nos discursos, eleva-se uma discussão entre positivismo vs pósmodernismo.

Nessa perspectiva, o objetivo deste trabalho é discutir as principais críticas voltadas ao modelo dominante de ciência - tido como positivista - com o propósito de fornecer um contraponto, ora reconhecendo as limitações inerentes a qualquer forma de produção de conhecimento, ora oferecendo uma releitura dessas críticas, à guisa de resposta. Para tanto, o texto inicia marcando uma posição firme contra o uso do termo (ou conceito) positivismo para se referir à epistemologia contemporânea (hegemônica) da ciência. É feito, portanto, um breve apanhado histórico, contextualizando a filosofia positivista enquanto movimento delimitado temporalmente, com a elaboração de um resgate das similitudes que fundamentam esse movimento. Da mesma forma, são pontuados alguns divisores de águas entre o positivismo e a ciência contemporânea (com destaque para a epistemologia de Popper e seu critério de demarcação).

Apesar de o rótulo não ser apropriado, as críticas à epistemologia contemporânea independem dele e são pertinentes. Nesse sentido, tais críticas são apresentadas e discutidas. Algumas são refutadas face à sua fragilidade, e outras, aceitas como limitações ao modelo de ciência criticado.

O texto termina com uma análise do chamado relativismo epistemológico, que fundamenta boa parte do chamado pós-modernismo, ao tentar articular conceitos como complexidade, linearidade e caos. 
Epistemologia contemporânea: solidificando o ideal científico

A Psicologia é uma ciência marcada por distintas abordagens que reivindicam diferenciais metodológicos e, em conseqüência, demarcam dissimilitudes conceituais e epistemológicas. A hegemonia da visão de ciência adotada, que se fundamenta no modelo das chamadas ciências exatas ou naturais, tem subvertido a um papel secundário as áreas que, por diversos motivos, adotam uma abordagem metodológica de fundamento epistemológico relativista. Nas suas críticas mais contundentes, autores como Gonzáles Rey (1999a, 1999b e 1997), Koch (1981) e Feyerabend (1985) têm rotulado esse modelo dominante de positivismo, devido à presença de alguns traços comuns. Essa é uma posição delicada, pois tende a atribuir semelhanças a áreas cuja interseção, no campo epistemológico-metodológico, é mínima. De maneira geral, o termo é inadequado, por três aspectos:

a circunscrição temporal do positivismo enquanto corrente filosófica;

- o seu critério de demarcação e o sentido de investigação;

os problemas em agregar áreas distintas sob a mesma égide.

Cada um desses aspectos é abordado, de forma sucinta, a seguir.

\section{A circunscrição temporal do positivismo}

O positivismo foi um movimento de pensamento que dominou parte da cultura européia (filosofia, artes, literatura) de aproximadamente 1840 até a 1a Guerra Mundial. O termo foi cunhado devido ao período de paz reinante na Europa e à expansão colonial na África e Ásia, que gerou um clima de entusiasmo em torno da idéia de progresso humano e social irrefreável.

Os feitos da revolução industrial, de acordo com Reale (1981), ocorreram em concomitância e tiveram grande influência na transformação social. A multiplicação das grandes cidades, o aumento da produção e da riqueza, a quebra do equilíbrio cidadecampo e a superação das grandes doenças infecciosas pela Medicina são alguns exemplos que fundamentavam essa crença. É preciso observar que não se tratava de um otimismo ingênuo que ignorava os subprodutos do desenvolvimento industrial. Os males sociais apontados pelo marxismo (proletariado, concentração financeira nas mãos de poucos, intensa jornada de trabalho) possuíam outra interpretação, aos olhos dos positivistas: eram “... fenômenos transitórios elimináveis pelo crescimento do saber, da educação popular e da riqueza" (Reale, 1981, p. 296). Assim, predominava a idéia de que era possível que a ciência elaborasse instrumentos para debelar todos os problemas da humanidade, até porque, e principalmente, o modo de produção era fortemente influenciado pela ciência.

Enquanto corrente filosófica, o positivismo influenciou diferentes produções humanas e situou-se em tradições culturais distintas: França (inseriu-se no racionalismo) - de Descartes a Auguste Comte; Inglaterra (tradição empirista e utilitarista) - John Stuart Mill e Herbert Spencer; Alemanha (cientificismo e monismo materialista) - Ernst Heckel e Jakob Moleschott; Itália (naturalismo renascentista) - Roberto Ardigò, e demarcou, antes de tudo, o espírito da época. No entanto, apesar das diversificações apresentadas, o positivismo apresenta similitudes que permitem identificá-lo como movimento de pensamento. Tais convergências podem ser enumeradas da seguinte forma:
O positivismo foi um movimento de pensamento que dominou parte da cultura européia (filosofia, artes, literatura) de aproximadamente 1840 até a $1^{a}$ Guerra Mundial. 
ao contrário do idealismo, o positivismo reivindica o primado da ciência: nós conhecemos somente aquilo que as ciências naturais nos dão a conhecer - o único método de conhecimento é o das ciências naturais;

- esse método (leis causais e domínio sobre os fatos) pode ser utilizado para o estudo da sociedade;

- afirma a unidade do método científico e o primado desse método como instrumento cognoscitivo;

- exalta a ciência como o único meio em condições de resolver, ao longo do tempo, todos os problemas humanos e sociais;

- pronuncia-se pela "divindade" do fato, o que induziu alguns estudiosos a interpretarem o positivismo como parte integrante da mentalidade romântica;

- toma alguns aspectos da tradição iluminista: a tendência a considerar os fatos empíricos como a única base do verdadeiro conhecimento, a fé na racionalidade científica como solução dos problemas da humanidade e a confiança acrítica, leviana e superficial na estabilidade e no crescimento sem obstáculos da ciência.

A obra de Auguste Comte, por ser um marco do positivismo, pode auxiliar a entender as características que influenciaram alguns preceitos que são encontrados (e são hegemônicos) nas ciências até hoje.

\section{Auguste Comte: filosofia positiva}

Comte estava preocupado com a resolução das crises sociais e políticas, e acreditava que o caminho consistia no conhecimento dos fatos sociais e políticos. Esse conhecimento somente pode ser adquirido ao se submeter a sociedade a um estudo rigoroso/pesquisa científica. Por esse motivo, toma como tarefa urgente desenvolver a chamada "física social" ou Sociologia científica. Para Comte, a ciência tem, como objetivo, pesquisar as leis que regem os fenômenos: "só o conhecimento das leis dos fenômenos, cujo resultado constante é o de fazer com que possamos prevê-los, evidentemente pode nos levar, na vida ativa, a modificá-los em nosso benefício" (Comte, 1988). Esse talvez seja o ponto mais prático da filosofia positivista. Mais em Stuart Mill que em Comte, essa forma de pensar se concretiza no utilitarismo. Nessa perspectiva, a lei é necessária para prever, e a previsão é necessária para agir sobre a natureza, fornecendo ao homem o domínio sobre esta última - "ciência, logo previsão; previsão, logo ação" (Comte, 1988).

Contudo, seria errôneo afirmar que Comte concebe que a ciência esteja essencialmente voltada para os conhecimentos práticos. Ao contrário, ele defende a natureza teórica dos conhecimentos científicos (distinguindo-os dos conhecimentos técnico-práticos). A relação entre a teoria (explicação das leis) e o fato é essencial. Segundo Comte (1988), “... a verdadeira ciência (...) consiste essencialmente de leis e não mais de fatos, embora estes sejam indispensáveis para o seu estabelecimento e sua sanção". Em conseqüência, consiste em leis controladas com base nos fatos, excluindose, da ciência, toda busca de essências e causas últimas metafísicas.

Por coerência, a Sociologia, como física social, baseia-se no conhecimento feito de leis provadas com base nos fatos. Para a Sociologia, através do raciocínio e da observação, é possível estabelecer as leis dos fenômenos sociais, como a Física pode estabelecer as leis que guiam os fenômenos físicos.

Em Comte, os caminhos para alcançar o conhecimento sociológico são a observação, o experimento (altera o nexo normal dos 
acontecimentos) e o método comparativo (estuda as analogias e as diferenças entre as diversas sociedades e os seus estados de desenvolvimento). É possível identificar, em Comte, os princípios positivistas (Figura 1) que influenciam a ciência tradicional bem como reconhecer sua contribuição às ciências sociais ao sugerir uma física social.

busca pelas leis que regem os fenômenos;

fato aparece como supremo e essencial para a elaboração das leis;

busca de objetividade;

- exclusão de explicações metafísicas para o fenômeno;

a observação e o experimento tornam-se instrumentos para alcançar o conhecimento.

Figura 1 - Princípios positivistas na obra de Comte

Da mesma forma, outros autores, como Florestan Fernandes, marcaram suas tentativas de fundamentar uma sociologia científica, atribuindo o caráter de ciência às áreas de humanidades (Oliva, 1997).

Como outros sistemas filosóficos, o positivismo está demarcado temporalmente e parece pouco adequado pressupor que ele sobreviva hoje, mesmo com rótulos mais modernos, como "neopositivismo".

Apesar de circunscrito historicamente, não se nega que o positivismo influencie o modelo hegemônico de ciência. Contudo, é factível considerar que a epistemologia atual das ciências sociais seja positivista?

\section{O critério de demarcação e o sentido de investigação}

Para responder à questão formulada, é pertinente discutir o critério de demarcação do positivismo e a ruptura proposta por Popper, bem como o sentido de investigação (indutivo vs. dedutivo), uma vez que marcam uma diferença crucial no que tange à construção do conhecimento e sua validade. A relevância de Popper, nesta discussão, é determinada pela influência que a conduta de investigação científica por ele proposta exerceu tanto nas áreas humanas quanto nas exatas (Pereira, 1993; Magee, 1973; Fearn, 2001), marcando uma ruptura com o verificacionismo e o indutivismo - traços marcantes do pensamento positivista.

Alguns autores consideram Popper, ainda hoje, um filósofo da ciência cuja origem se debruça sobre os mesmos problemas que interessavam aos adeptos do positivismo lógico. Uma vez que os positivistas lógicos estavam determinados a afastar a metafísica do procedimento científico, eles se preocupavam com a questão do significado, que, em última instância, traz, como critério de demarcação, a sua suscetibilidade de verificação empírica (Magee, 1973).

Conforme dito anteriormente, uma característica que marca uma diferença fundamental de Popper para com o positivismo lógico é a superação do verificacionismo. Ele propõe uma metodologia que privilegia o experimento a partir de hipóteses elaboradas com base no conhecimento científico produzido e acumulado. Nesse sentido, “... Popper jamais foi um positivista de qualquer matiz; ao contrário, foi um antipositivista decidido, o homem que, desde o princípio, adiantou os argumentos que produziram (depois de um tempo excessivamente longo) o esfacelamento do positivismo lógico" (Magee, 1973, pp. 50-51), e nem poderia sêlo, uma vez que, ao longo de sua obra, busca demonstrar a fragilidade de solidificar uma ciência baseada no acúmulo de dados e em verdades absolutas.

Por esse motivo, Popper propõe a falseabilidade como novo critério de demarcação científica (Chauí, 1999; Feijó, 2003; Pereira, 1993; 
Popper, 1972). O conhecimento passa a ter uma natureza provisória, ou seja, não é possível demonstrar que aquilo que sabemos é verdadeiro, mas é sempre possível que o conhecimento se revele falso. Nada, na ciência, está permanentemente estabelecido ou é inalterável. É a partir da experimentação de hipóteses refutáveis, negando ou aceitando-as, que a teoria é construída.

Segundo Popper (1972), as teorias não são corpos de fatos impessoais a respeito do mundo, mas produtos do espírito humano. Essa característica as transforma em conquistas individuais surpreendentes, contudo, a criação científica não pode se dar tão livremente quanto a criação artística. É preciso ter um minucioso confronto com a experiência. Uma teoria deve, antes de tudo, propiciar solução para um problema que nos interesse. Deve mostrar-se compatível com todas as observações feitas e incluir as teorias anteriores (contradizendo suas falhas e apontando soluções).

"A teoria do conhecimento de Popper está intimamente associada a uma teoria da evolução" (Magee, 1973, p. 58). A eliminação dos erros redunda na chamada seleção natural - ou seja, o organismo/teoria não sobrevive na ausência de uma transformação necessária ou em virtude de uma transformação errada, bem como na ausência de controles que modifiquem ou suprimam transformações inadequadas. Tais transformações somente podem ocorrer em um processo que teste a teoria (ou parte delas) e não em um que busque a sua comprovação.

No processo indutivo, cada caso confirmador eleva o seu grau de probabilidade. Assim, as leis científicas são prováveis no mais alto grau que se possa conceber a ponto de não se distinguir da certeza, por isso Popper rompe com o traço indutivo, que era o critério de demarcação entre a ciência e a não ciência, e propõe o dedutivo. As principais dessemelhanças, no que tange ao método, podem ser verificadas na Figura 2.

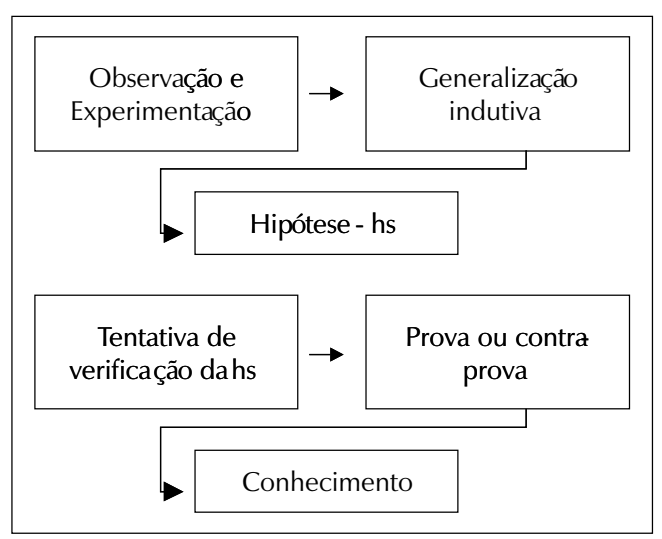

Positivista (Magee, 1973)

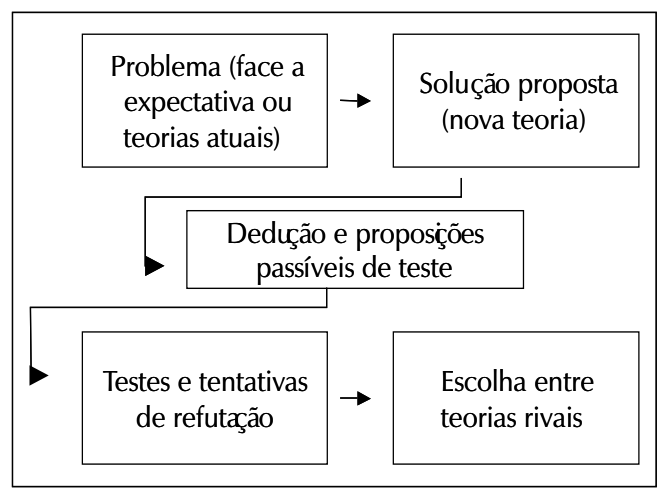

Popper (Magee, 1973)

Figura 2 - Concepção positivista (indutiva) vs concepção popperiana (dedutiva)

Ao observar o processo de construção do conhecimento, nota-se que a concepção hipotético-dedutiva de Popper se diferencia pelo papel que o dado empírico assume (Feijó, 2003). Ao contrário da concepção positivista, somente após uma análise da teoria, que implica um repensar do conhecimento posto, surge um problema. Este deve ser convertido em proposições testáveis, elaborando-se um delineamento/experimento e, somente então, vai-se ao empírico.

Pode-se perceber que Popper deu atenção especial às teorias, e esse foi um dos seus 
legados para a epistemologia contemporânea. Os fatos se constituem em um norte sinérgico a ser respeitado a fim de reduzir a subjetividade do processo, porém eles não são postos em um lugar que efetive uma prostração teórica.

A ruptura proposta, calcada no papel da teoria, em particular da hipótese, dá condição à ciência de negar o que está posto (ou de assumi-lo como provisório), em vez de trabalhar sempre em prol da comprovação e da manutenção de "verdades". Há efetivamente uma mudança no processo de investigação, entre o positivismo (indutiva) e a epistemologia contemporânea (dedutiva). Ainda que a epistemologia contemporânea tenha, no seu fundamento, uma ruptura, ela possui características herdadas do positivismo. Tais características não são suficientes para denominar de positivistas diferentes concepções de produção do conhecimento em ciências sociais.

\section{Os problemas em agregar áreas do conhecimento distintas sob a mesma égide}

O principal argumento dos autores relativistas para considerar a epistemologia contemporânea como positivismo está embasado nas semelhanças encontradas em princípios como:

- a busca pela objetividade, que pressupõe uma neutralidade por parte do pesquisador em relação ao objeto;

- a utilização de instrumentos voltados à quantificação, que, ao fornecer informações objetivas, leva à pretensão de centrar no fato/dado o papel principal na construção do conhecimento.

Contudo, apesar de o positivismo e de a epistemologia contemporânea possuírem traços comuns, eles têm diferenças importantes e marcantes, conforme discutido no tópico anterior. Ao buscar as similitudes e reduzi-las a um mesmo sistema, disciplinas que compartilham alguns desses traços podem ser vistas como positivistas, embora divirjam desde a forma de compreender o objeto até o delineamento de pesquisa e construção do saber.

A Figura 3 traz um resumo das características do positivismo, que aparecem na obra de Comte e que ainda hoje podem ser vistas no modelo científico hegemônico, contrapondo-as a três grandes sistemas ligados à Psicologia (Psicologia social, psicanálise e Psicologia comportamental).

\begin{tabular}{|c|c|}
\hline Características comuns: & \\
\hline (1 Objetividade & Sistemas \\
\hline 2 Linearidade & (2) 35 Psicologia social \\
\hline (3) Instrumentalização/quantificação & (4) Psicanálise \\
\hline 4 Causalidade & (12345 Comportamentalismo \\
\hline (5) Supremacia do fato & \\
\hline 6 Método indutivo & \\
\hline
\end{tabular}

Figura 3 - Características do positivismo e sistemas da Psicologia 
Um dos pontos mais relevantes nas críticas dirigidas à epistemologia contemporânea diz respeito ao número de elementos, em diversos níveis, que se integram para formar um determinado fenômeno.
Pode-se perceber, ao analisar a figura acima, que algumas características (à esquerda) atribuídas ao positivismo são comuns a mais de um sistema (à direita). De fato, Gonzáles Rey (1999a, p. 19) destaca a objetividade como uma das características da psicanálise (herdada de uma visão organicista, fisiológica/ biológica e naturalista de Freud), embora o mesmo autor admita e enfatize que as premissas das duas áreas são efetivamente distintas. Da mesma forma, a Psicologia social e o comportamentalismo possuem algumas características em comum que poderiam facilmente reduzi-los a um mesmo referencial. Contudo, a própria natureza dos fatos analisados (em laboratório, sob rigor experimental e em campo, submetidos às características do ambiente) torna os conhecimentos produzidos distintos entre si. Em alguns casos, a diferença é maior que a similitude.

Sozinhos, os argumentos utilizados não permitem uma conclusão categórica, contudo, em conjunto, apontam a fragilidade de colocar o rótulo de positivismo na demarcação científica contemporânea. Não obstante, vale insistir que, mesmo que estejam coerentes, as críticas destinadas à epistemologia hegemônica, em primeiro plano, e à sua metodologia, em segundo, merecem ser consideradas.

\section{Críticas à epistemologia contemporânea}

É por merecerem atenção que se justifica discutir as principais críticas. Aqui, pretendese apenas pontuá-las, a fim de fornecer um quadro geral sobre o tema, sem esgotá-lo, mas de maneira que ele seja representativo. Esta seção foi organizada com o intuito de apresentar diferentes argumentos divididos nas temáticas: (a) complexidade e reducionismo, (b) o papel das idéias e a objetividade e (c) rigidez metodológica.
Embora divididos dessa forma, esses temas, de fato, se integram. Logo, a estratégia adotada neste artigo visa somente a propiciar momentos de inteligibilidade que permitam um contraponto, sobre o qual, após os argumentos, serão realizadas discussões que esclarecerão alguns pontos e/ou apresentarão discordâncias.

\section{Complexidade e reducionismo}

O eixo principal das críticas relativas à complexidade trata da simplificação, a priori, do objeto de estudo, e estão presentes nas obras de Gonzáles Rey (1999a, 1999b, 1997) e Feyerabend (1985), quer ditas dessa forma, quer buscando explicitar os princípios positivistas. Essa simplificação implica separar os fenômenos em variáveis cujas relações devem ser testadas.

Um dos pontos mais relevantes nas críticas dirigidas à epistemologia contemporânea diz respeito ao número de elementos, em diversos níveis, que se integram para formar um determinado fenômeno.

No caso da Psicologia, a complexidade se manifesta, uma vez que seu objeto é um sujeito em inter-relação com outros sujeitos e/ou com seu ambiente. Segundo Koch (1981), as características dos eventos psicológicos, como sua multideterminação, ambigüidade do ser humano e do ambiente contribuem para essa complexidade. Assim, elaborar "recortes" onde algumas variáveis são controladas e outras manipuladas para teste permite propor modelos explicativos, porém pouco representativos da realidade.

Para Feyerabend (1985, p. 20), "um meio complexo, onde há elementos surpreendentes e imprevistos, reclama procedimentos complexos e desafia uma análise apoiada em regras que foram estabelecidas de antemão..." A interpretação que subjaz a essa afirmação é que qualquer tentativa, nesse sentido, tende, necessariamente, a ser reducionista, levando 
a explicações parciais, e deve ignorar elementos relevantes à compreensão do fato.

Pode-se verificar, também, que esse reducionismo marca uma diferença essencial no que tange ao papel da teoria na construção do conhecimento. Na epistemologia contemporânea, a teoria é o local onde as relações entre variáveis são discutidas em função do problema. Nesse contexto, de acordo com Gonzáles Rey (1999a), a teoria deve estar "...presente como instrumento do investigador em todo o processo interpretativo, porém não como conjunto de categorias a priori, capazes de dar conta dos processos únicos e imprevistos que aparecem na investigação..."

Percebe-se que as críticas - aqui foram citados trechos representativos das mesmas assumem que a complexidade do fenômeno não pode ser contemplada estudando suas partes e depois tentando juntar as peças como em um mosaico. O interessante é que, a partir da compreensão da profundidade dessa crítica, é possível resgatar o valor da teoria e da complexidade para a epistemologia contemporânea. A teoria, vista como um conjunto de enunciados que explicam o fenômeno e que foram submetidos a testes experimentais ou verificações, fornece uma base sólida para a delimitação das variáveis e a elaboração das hipóteses. Logo, embora o método permita que a sua hipótese seja gratuita (ou seja, possa estar calcada em um aspecto metafísico ou na realidade), via de regra, é uma teoria que guia os problemas de pesquisa. A simplificação, ou melhor, o recorte, é feito antes da investigação, mas não antes de se possuir uma base sólida - seja de uma revisão bibliográfica, seja de um estudo preliminar.

Com relação à complexidade, a pósmodernidade presta um favor ao aconselhar repetidamente que uma investigação deve estar atenta a esse aspecto. Todavia, a maneira pela qual a ciência contemporânea a realiza é, de fato, lenta. Trata-se de juntar novos elementos às descobertas feitas, não como um mosaico, mas estabelecendo também as inter-relações entre as diversas variáveis no contexto (abarcando seus diferentes níveis). Ela (a complexidade) é de fato alcançada? Não! E, categoricamente, nem pela visão hegemônica, nem pelas alternativas propostas. Chegar mais perto dela (se é que é possível) é o bastante para caracterizar uma ou outra como melhor?

A diversidade dos fenômenos que envolvem o sujeito como objeto é vasta, logo, vasta deve ser a forma de abordá-lo para abraçá-lo em muitas dimensões.

Uma última palavra sobre o reducionismo: um olhar amplo para contemplar toda a complexidade é per se também reducionista, uma vez que a busca pelo todo ignora as relações entre as 'variantes/variáveis' que constituem o objeto.

\section{O papel das idéias e a objetividade}

Essa talvez seja a crítica mais contundente, já que reúne, ao mesmo tempo, a questão da tentativa de obter conhecimentos objetivos do fenômeno - que implica, na verdade, reduzir a subjetividade - e trata do papel que as idéias assumem na produção do conhecimento.

No que tange à objetividade, uma indagação perpassa todos os argumentos: como pode o pesquisador manter a imparcialidade, se o contato com o sujeito investigado, por si mesmo, altera a percepção, as atitudes e o comportamento de ambos?

Não há como se isolar de maneira a não influenciar o experimento e, portanto, o conhecimento produzido. Argumentos de significado semelhante podem ser encontrados em Gonzáles Rey (1999a e 1997) e Glasersfeld (1994). De fato, é possível encontrar esse argumento mesmo em Morin 
(1991), quando este discute o papel da cultura na sociedade humana e em Maturana, quando este discute o fenômeno da ação.

De acordo com Ibañez (em Gonzáles Rey, 1999, p. 32), “... se alguém investiga sistemas muito objetivos... implicitamente segue o princípio da objetividade, porém os investigadores sociais se encontram com objetos que são sujeitos com a mesma capacidade distincional e objetivadoras que eles mesmos". É explícita aqui a idéia de que a presença do pesquisador, ou mesmo a sua intervenção em qualquer que seja o nível, exerce influência sobre o objeto. Aliás, esta tem sido uma das grandes dificuldades para a Psicologia, principalmente para as pesquisas que adotam o modelo hegemônico: observar e testar provocando alterações mínimas no fenômeno.

Ao considerar que não há como eliminar essa influência, que, em todo caso, possui um caminho de duplo sentido, ou seja, o pesquisador também está sujeito a ela, é coerente acreditar que a objetividade almejada fica comprometida, quiçá seja uma meta inatingível. Um dos caminhos possíveis para resolver essa questão é buscar suprimir, ou melhor, reduzir a subjetividade do investigador. No entanto, critica-se a redução do espaço que este tem para produzir idéias e descartam-se elementos que surgem no decorrer da investigação. Então, a produção teórica se torna limitada, pois o empírico assume um lugar de destaque, determinando uma supressão da elaboração intelectual para explicar os fatos e concatená-los com outras expressões do mundo. Nesse sentido, “...tem sido o empirismo característico da epistemologia positivista um dos fatores que tem impedido aos investigadores qualitativos ver que o ponto forte de uma representação metodológica alternativa é precisamente reconhecer o status das idéias, da produção teórica como atributo essencial da produção do conhecimento. Isso supõe outorgar um lugar diferente ao empírico na compreensão da ciência" (Gonzáles Rey, 1999, p. 15).

Embora esse raciocínio seja circular, é preciso considerar que a subjetividade deve retomar espaço, uma vez que, se o pesquisador não pode ter acesso direto ao fenômeno, tudo o que ele conhece é fruto da interpretação, logo, é fruto também de um processo de maturação do pesquisador no que tange ao seu psiquismo e sua história. Feyerabend (1985) faz essa relação quando ressalta que "...a história da ciência não consiste apenas de fatos. Contém (...) idéias, interpretações de fatos, problemas criados por interpretações conflitantes, erros (...). Análise mais profunda mostra que a ciência não conhece 'fatos nus', pois os fatos de que tomamos conhecimento já são vistos sob certos ângulos essencialmente ideativos". Assim, mais que atribuir ao sujeito e/ou ao pesquisador uma singularidade, é necessário tornar a subjetividade foco da investigação, isso porque, no argumento de Gonzáles Rey (1999a, p. 45), a "...singularidade não aparece como uma exceção no domínio da subjetividade: ela é um momento qualitativo constituinte da subjetividade".

Na mesma linha de raciocínio, a busca pela objetividade faz com que os pesquisadores tentem garanti-la por meio de um delineamento reducionista e pelo desenvolvimento de instrumentos padronizados em que a estatística procura garantir fatores como validade e confiabilidade. Gonzáles Rey (1999a, p. 45) aponta limitações nesses instrumentos, afirmando que as diferenças de processos psíquicos complexos, tais como criatividade e aprendizagem, não podem ser definidas "...através de modelos quantitativos que consideram o estudado como uma entidade homogênea, que variam somente em atributos pontuais..." abordados pelos testes psicológicos.

Novamente as críticas efetuadas são pertinentes e devem ser consideradas. No 
entanto, tais considerações não passam ao largo dos pesquisadores adeptos da ciência contemporânea. Ao contrário, não se busca negar a intencionalidade dos sujeitos nem desconsiderar as diferenças intra e interindividuais, mas considerar que existem padrões de comportamentos entre esses sujeitos singulares. O próprio êxito dessa dicotomia "Sujeito-Objeto" dá mostras da sua eficácia. Essa dicotomia não é cega às influências da subjetividade dos sujeitos; esta é considerada nas margens de erro e nos mecanismos metodológicos que os detectam. Admite-se, hoje, que os testes não garantem uma medida segura para a previsão ou análise do comportamento e/ou atitude do sujeito. Continua-se, no entanto, tentando desenvolver novos instrumentos e técnicas que reduzam esses efeitos e garantam um conhecimento que permita agir para melhorar a vida dos sujeitos. Contudo, ainda que todos os estudos que foram realizados segundo esse método de construção do conhecimento tivessem fracassado, faz parte do mecanismo científico o falseamento e a identificação de falhas e erros e a sua superação por um novo estudo ou modelo mais factível.

\section{Rigidez metodológica}

A rigidez metodológica está relacionada ao delineamento elaborado para garantir:

uma intervenção objetiva;

- que as relações entre as variáveis possam ser consideradas verdadeiras.

De certa forma, os problemas dessa inflexibilidade já foram abordados anteriormente, como: a exclusão de elementos relevantes à compreensão do fenômeno que são ignorados no decorrer da pesquisa, o reducionismo do fenômeno em variáveis e a restrição das idéias, que leva à elaboração de microteorias (ignorando a complexidade do fenômeno), no entanto, um aspecto desse tema merece destaque, dado o problema posto: a própria rigidez leva o pesquisador a elaborar táticas que possam flexibilizar suas ações a fim de conduzir a investigação. Destarte, Feyerabend (1985) assume que "...não há uma só regra, embora plausível e bem fundamentada na epistemologia, que deixe de ser violada em algum momento (...) não eventos acidentais... ou desatenção, ao contrário, são necessários para o progresso". Esse argumento pode sugerir, em um primeiro momento, que a objetividade almejada não é alcançada, e mais, que o conhecimento produzido sob esse modelo pode ser refutado no sentido de não controlar as variáveis envolvidas no fenômeno.

Vale destacar, todavia, que qualquer rigidez mencionada se deve à tentativa de não mudar o sentido de investigação mantendo controle sobre as variáveis em análise. Não se pode confundir esse controle com a negação obtusa de que outras variáveis, aparentes ou não, sejam determinantes do fenômeno. A inclusão destas deve ser feita em um outro momento. Nada impede que os outros determinantes sejam mencionados na discussão ou que se proceda a um segundo plano de pesquisa em inter-relação com o principal para verificar correlações.

Aliás, esse caráter serendípico, do acaso, permeia o avanço científico. O mérito do pesquisador, nesse caso, é ser criativo o suficiente para estudar a nova variante sem descaracterizar seu delineamento.

De fato, o aspecto inflexível é mais uma tentativa de manter coesão interna e sistematização, a fim de não dar lugar a argumento como o de Feyerabend (1985, p. 296), que, ao falar sobre as limitações de todas as metodologias, afirma que "a única 'regra' que sobrevive é 'qualquer coisa serve'". Como afirmam Sokal e Bricmont (1999, p. 88), é ingenuidade acreditar que existam regras gerais que permitam falsear ou corroborar alguma 
coisa, independentemente do contexto. A criatividade para investigar, em quaisquer metodologias, variáveis intrínsecas aos sujeitos (comprometimento, criatividade, depressão), é um requisito importante na formação de bons pesquisadores.

\section{Conclusão}

Este trabalho tem a ambição de pontuar elementos de reflexão de que o emprego do termo positivismo (e todas as suas conseqüências) é impreciso como denominação para a epistemologia contemporânea. Diferentes argumentos foram articulados nesse sentido, mas, obviamente, a importância e complexidade do tema demandam reflexões sob diferentes pontos de vista.

Apesar de encontrar críticas abertas: (a) ao behaviorismo, associando-o ao positivismo (Gonzáles Rey, 1999a; Koch, 1981); (b) a Popper, associando o método dedutivo ao positivismo lógico (Gonzáles Rey, 1999) apesar de essa ser uma das suas maiores discrepâncias com o Círculo de Viena, e (c) à psicanálise, destacando seu caráter biológico e naturalista (Gonzáles Rey, 1999a; Popper 1972) - destacando-se a busca pela objetividade, não foi encontrado, na literatura, nenhum argumento tentando associar todas essas "escolas" a um mesmo referencial epistemológico. Nesse sentido, apesar de inovador, o terceiro argumento apresentado para não se enquadrar a epistemologia contemporânea dentro do positivismo deve ser mais bem fundamentado. Mas é um contra-ponto válido.

Koch (1981, p. 268) admite a diferença existente entre as muitas áreas da Psicologia e ao fato de haver, portanto, distintos recortes do fenômeno, o que implica estabelecer diferentes universos de discurso. Ao admitir essa variabilidade - filosófica e metodológica - é negativo o fato de tentar se destacar uma abordagem com a qual ninguém se identifica, pelo menos nominalmente. Como se buscou demonstrar, não se trata de escapar das críticas, mas de um rótulo agregador de dissimilitudes - e carregado de estereótipos mais pejorativos que elucidativos.

Outras críticas poderiam ter sido abordadas, como a influência da teoria do caos para a filosofia das ciências exatas, o princípio da incerteza e a quantidade de microteorias produzidas pelo modelo hegemônico na Psicologia. Contudo, o espaço e a limitação do próprio autor para discorrer sobre tais assuntos foram empecilhos à sua inclusão. Cabe, porém, ao menos demonstrar que não se está alheio a elas.

As críticas mais freqüentes na literatura passam a impressão de se ter o intuito, obviamente não é o único nem é explícito, de abrir passagem para uma nova forma de produzir conhecimento. Como a égide de ciência é um certificado de competência e validade, é natural que todos reivindiquem tal status e, para tanto, proponham seus critérios de demarcação.

Segundo Koch (1981), a maioria das abordagens em Psicologia, apesar ou por causa dos seus cem anos (na época do artigo), não se qualificam como ciência. Aliás, hoje, mesmo que mudassem os critérios para outros diametralmente opostos, ainda assim, grande parte das abordagens seria marginal.

Finalmente, mesmo Feyerabend, com o radicalismo manifesto em frases como: "o amor torna-se impossível para as pessoas que insistem na 'objetividade', isto é, que vivem inteiramente de acordo com o espírito da ciência" (em Sokal; Bricmont, 1999, p. 90), ressalta que o contexto e o fenômeno escolhido determinam a melhor abordagem e metodologia. Dito de outra forma, os conhecimentos produzidos nas diversas abordagens possuem critérios de realidade distintos, mas uns não são melhores ou piores do que os outros. 


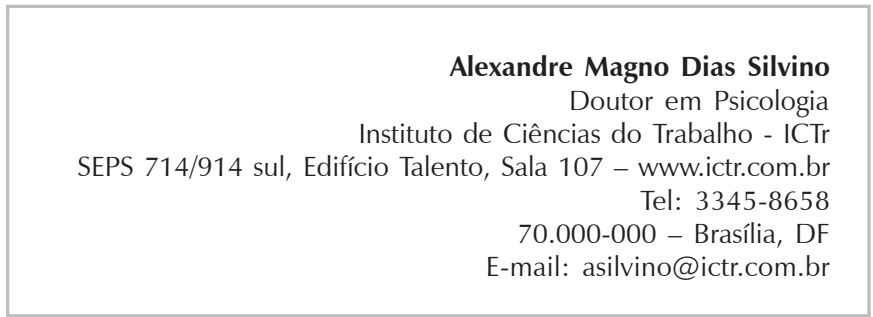

Recebido 25/04/06 Reformulado 28/08/06 Aprovado 11/09/06

CHAUÍ, M. Convite à Filosofia. São Paulo: Editora Ática, 1999.

COMTE, A. Curso de Filosofia Positiva. São Paulo: Nova Cultural, 1988.

FEARN, N. Aprendendo a Filosofar em 25 Lições. Do Poço de Tales à Desconstrução de Derrida. Rio de Janeiro: Jorge Zahar Editor, 2004.

FEIJÓ, R. Metodologia e Filosofia da Ciência: Aplicação na Teoria Social e Estudo de Caso. São Paulo: Editora Atlas, 2003.

FEYERABEND, P. Contra o Método. Rio de Janeiro: F. Alves Editora, 1985.

GLASERSFELD, E. Despedida de la Objetividad. Editorial Gedisa:Barcelona, 1994.

GONZÁLES REY, F. La Investigación Cualitativa en Psicologia: Rumbos y Desafios. São Paulo: EDUC, 1999(a).

GONZÁLES REY, F. La Afectividade desde una Perspectiva de la Subjetividad. Psicologia:Teoria e Pesquisa, Brasília, v. 15, no 2 , pp.127-134, 1999(b).

GONZÁLES REY, F. Epistemología Cualitativa y Subjetividad. São Paulo: EDUC, 1997

$\mathrm{KOCH}, \mathrm{S}$. The Nature and Limits of Psychological Knowledge. Lessons of a Century Qua "Science". American Psychologist, WasghingtonDC, 36(3), pp.257-269, 1981.
MAGEE, B. As Idéias de Popper. São Paulo: Editora da Universidade de São Paulo, 1973.

MORIN, E. Introdução ao Pensamento Complexo. Lisboa: Instituto Piaget, 1991.

OLIVA, A. Ciência e Ideologia. Florestan Fernandes e a Formação das Ciências Sociais no Brasil. Porto Alegre: EDIPUC, 1997.

PEREIRA, J. C. R. Epistemologia e Liberalismo. Uma Introdução à Filosofia de Karl R. Popper. Porto Alegre: EDIPUC, 1993.

POPPER, K. R. A Lógica da Pesquisa Científica. São Paulo: Cultrix, 1972.

REALE, G. História da Filosofia. O Positivismo. São Paulo: Paulus, 1981.

SAGAN, C. O Mundo Assombrado pelos Demônios. A Ciência Vista como uma Vela no Escuro. São Paulo: Companhia das Letras, 1998.

SOKAL, A.; BRICMONT, J. Imposturas Intelectuais. O Abuso da Ciência pelos Filósofos Pós-modernos. Rio de Janeiro/São Paulo: Editora Record, 1999. 